\title{
MODELLING RATE OF TRAFFIC-INDUCED BUILDING VIBRATIONS IN SANGO-OTA, NIGERIA: AN ASSUMPTION BASED ANALYSIS
}

\author{
OLUSEYI OLANREWAJU AJAYI ${ }^{1}$, MICHAEL CHIKODI AGARANA ${ }^{2,3}$, ISAAC IBUKUN AKINWUMI ${ }^{4}$, \\ PRINCESS IMHADE OKOKPUJIE ${ }^{1}$, ENESI YEKINI SALAWU ${ }^{1}$, ABIODUN AYODEJI ABIOYE ${ }^{1}$, \\ ADENIRAN SUNDAY AFOLALU ${ }^{1} \&$ RICHARD OLUFEMI LERAMO ${ }^{1}$ \\ ${ }^{1}$ Department of Civil Engineering, Mechanical Engineering Department, Covenant University, Nigeria \\ ${ }^{2}$ Mathematics Department, Covenant University, Nigeria \\ ${ }^{3}$ Department of Mechanical Engineering Science, University of Johannesburg, South Africa \\ ${ }^{4}$ Department of Civil Engineering, Covenant University, Nigeria
}

\begin{abstract}
This work investigates the phenomenon of transport induced building vibrations in the study area with a view to creating suitable model which can be used at any time to predict the extent of building oscillations created by vehicular movements on adjacent roads, based on 'the volume of heavy vehicle traffic hypothesis. Series of interviews were conducted and a randomized manual volumetric heavyvehicle traffic counts were carried out at one of the sites used for the study. Results showed that $100 \%$ of the respondents agreed to the stated effects of vehicle transportation, which include noise, vibrations, accidents and carbon monoxide emissions while $86.7 \%$ agree that traffic-induced building vibrations are caused by heavy vehicular movements within the study areas. The outcome of the volumetric count was employed with suitable assumption that is based on the volume of heavy vehicle traffic hypothesis to develop a model for predicting rate of traffic-induced building vibrations. This model can also be used to predict extent of damage when the damage parameters resulting from such individual vibrations are known. This study is used to show a pathway to predicting extent of annoyance which can result from vehicular movements in an area.
\end{abstract}

Keywords: traffic count, model, probabilistic, regression analysis, building vibrations.

\section{INTRODUCTION}

Transportation can be simply defined as the movement of people, goods and services from one place to another, with system consisting of fixed facilities, flow entities and control systems that permit the free flow and efficient movement of people and goods from place to place across geographical boundaries. It provides the connectivity that facilitates other societal interactions and also acts as a functional system in its context of providing service [1]. Moreover, the economic scope of transportation system in recent times is of paramount interest in designing efficient system and networks for adequate delivery. The investments in transportation takes place because they are seen as enhancing the profitability of investments in other areas of the economy and also promoting interactions among nations, communities, and individuals [1]-[3]. Although it has been suggested that, it is very difficult to measure the exact impact of transport investment on development because of its subtle, yet complex nature of the role it plays in economic development [4], its role in urban development and inter as well as intra community trade cannot be downplayed, as it serves to enhance the movement of goods and services from source to point of need [4], [5].

Transportation development in Nigeria started from the use of animals earlier than the 1800 s and gradually moved into the era of using rail to transfer people and goods from a city to another as far back as the 1800s [6]. This use of rail was continued and further developed throughout the colonial era. Automobiles as means of transportation started way back in 1907, when only two vehicles were introduced and used in the city of Lagos [6]. The number 
of cars grew from that time to about 4,700 in 1963 competing favourably with rail transport system, and further with time became most prominent and most used by the 70s upward [6]. This period of automobile development enhanced the growth and advancement of industrialization and rapid urbanization. The use of automobiles as means of transportation is on the increase since the 70s. However, between mid-70s and 80s, when its use got an explosion, rail transportation was used mainly to convey goods from place to place, thereby, limiting the number of heavy vehicles plying the roads and highways. The destruction of this rail transportation due to lack of proper maintenance in the mid-80s, brought about an increased use of trucks to move goods on major and minor roads, thus, leading to traffic congestion, environmental pollution, and increased road accidents.

However, while the problems of road accidents and traffic congestion in Nigeria have gained most of the attention of government and individuals, that due to environmental pollution has not. Several solutions, based on available data and analysis, exist that points to the resolution of the issues of road accidents and traffic congestion [6]-[8]. Not much has been done to reduce the incidents of traffic induced environmental pollution. The totality of impact of traffic induced environmental pollution in Nigeria is in varying degrees of noise, carbon monoxide (CO) emission and induced building vibrations. At times, this impact could also be due to a combination of these sources. Vibrations induced in buildings are a major concern around the world, with many occupants of residential buildings complaining about annoying disturbances in their buildings as a result of the vehicular movements on adjacent roads. They are afraid that such perturbations arising from these movements could lead to damage of their buildings. Traffic vibrations are mainly caused by heavy vehicles and are induced as a result of the presence of discrete irregularities in roads surfaces and also imperfections in the vehicles. These irregularities and imperfections lead to dynamic interactions between the vehicles and pavements as well as with adjoining road structures, thereby leading to the creation of stress waves that cause vibrations [9]. These stress waves indirectly load the microstructure of the concrete, an aggregate composite [10], creating a cyclic stress within the building material, which if allowed to continue, can lead to the weakening of these buildings and probably fatigue. Fatigue on the other hand has been explained as the process by which a material fails under cyclic stresses below its maximum static strength [11]. It develops unnoticed from a tiny crack which if allowed to grow, propagates at a fast rate when conditions causing it to reach a certain critical stage [12]. Meaning that, if the number of trucks passing through these roads are allowed to continue to be on the increase while the buildings still remain as they are, the effect could be damaging and catastrophic. Many factors affecting vibration levels include road condition, vehicle weight and speed, vehicle characteristics, soil stratification and properties, and building characteristics. Some suggestions have also been made to reduce vibrations induced by traffic. These include periodic maintenance of road surfaces, traffic flow control, vehicle weight and speed control, soil improvements, vibration screening using in-ground barriers, use of vibration isolation systems, proper design of buildings, and improvements of road surface substructure [9].

Basically there are two types of traffic-induced vibrations: ground borne and airborne vibrations. The ground borne vibrations is due to the vehicle-pavement interactions while the airborne is due to the acoustic noise of vehicles or aircrafts which cause window rattling and annoyances [9]. Airborne vibrations occur at higher frequency than the ground borne vibrations and may also be caused by the interaction of the buildings with the large air pockets trailing heavy vehicles as they travel the road. Globally, the phenomenon of traffic-induced vibrations has been of concern, with earliest report around the 1920s [9]. Ever since then, many authors around the world have published concerns and findings on the subject [13]- 
[15], with none from Nigeria, yet the phenomenon exist in the country with daily occurrences. Moreover, investigating traffic-induced building vibrations with a view to report and agitate for solutions involve adequate funding and use of sophisticated and vibration sensitive equipment. These may be the bane of a lack of concentrated approach towards solving the phenomenon of traffic-induced vibrations in Nigeria. However, the need would always arise in the face of many complaints about the increasing building vibrations in the country. There is also a need to create a simple model for predicting the extent of traffic-induced vibrations, based on the volume of heavy vehicle traffic hypothesis. This hypothesis is based on an assumption that if of the total number of heavy vehicles (trucks, tippers and trailers) going through a particular road, a certain number (probably due to weight and size of vehicles, serviceability and maintainability, speed, and/or due to pavement conditions) causes building vibrations per hr/day, then the extent/rate at which vibrations would be induced into road side buildings could be extrapolated from the analysis of total vehicle phenomenon. This study was therefore used to capture the perception of people on the incidence of traffic-induced building vibrations in the study areas. It aims to investigate and develop a model to measure, predictively, the level of occurrence and determine the rate of annoyance per period of analysis. Thus, giving rise to a tool that can be used at any time to determine the extent at which an amount of heavy vehicle traffic would induce building vibrations. In additional to this, the study also focused on determining people's perception on the incidents of trafficinduced environmental pollution in the study areas.

\section{MATERIALS AND METHODS}

\subsection{Study areas}

To carry out this work, two study areas Iyana Joju road, Sango $\left(6.709^{\circ} \mathrm{N}, 3.237^{\circ} \mathrm{E}\right)$ (called site 1) and Iyana-Iyesi axis of Ota-Idiroko Express road, Ota $\left(6.681^{\circ} \mathrm{N}, 3.184^{\circ} \mathrm{E}\right)$ (called site 2 ) within Sango-Ota, Ogun State of Nigeria were picked. The choice of the sites was a result of the high volume of informal complaint received from the residents.

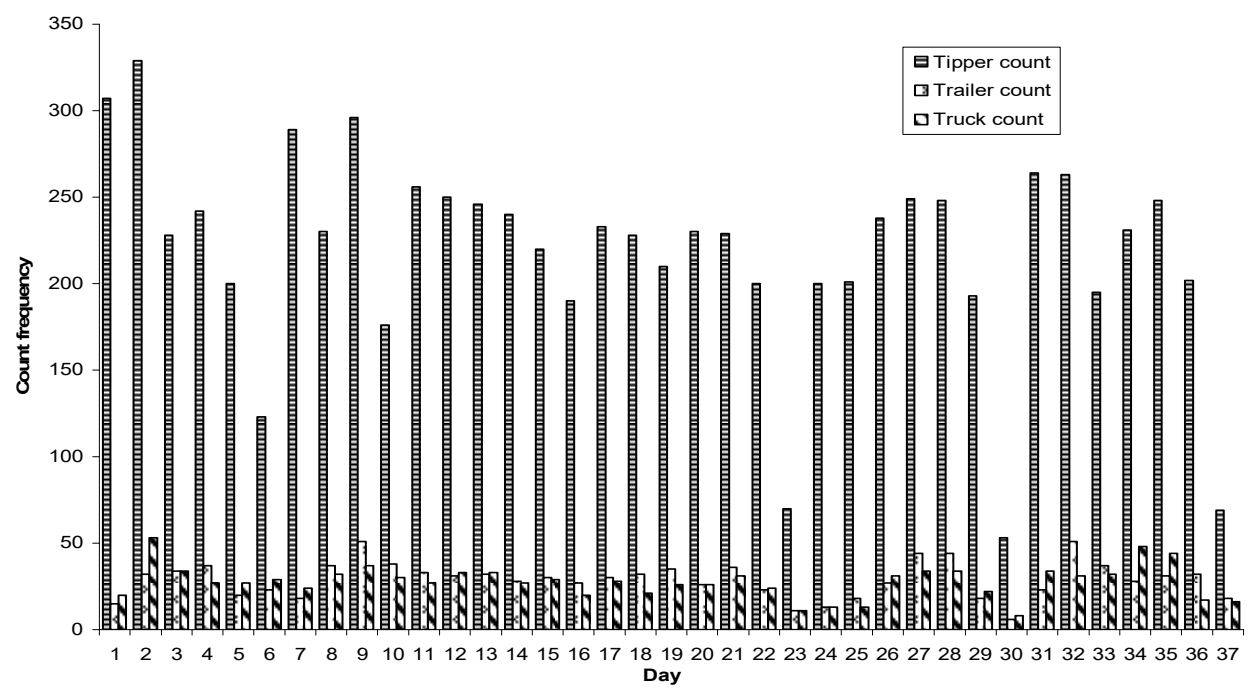

Figure 1: Transportation count of the individual heavy vehicle type per day. 


\subsection{Testing procedure}

The testing procedure involves manual traffic count, interviews and administration of questionnaires. The interviews and questionnaires were used to capture people's perception and opinion on the phenomenon of traffic-induced building vibrations and environmental pollution. Thus, series of interviews were conducted for residents of the study areas and a randomized manual volumetric heavy-vehicle traffic counts were carried out at site 1 . Site 1 was used for the vehicle count because most of the vehicle movements takes place around the site. On-site appraisal of the road conditions and frequency of heavy vehicle movement in the two sites were also done. Fig. 1 shows the manual volumetric count for the three heavy vehicles (Tipper, Trailer and Truck) prevalent in these areas and Fig. 2 shows the cumulative distribution of the heavy vehicle types per hour/day for the whole 37 days of data collection. The responses of residents from the sites as extracted from the questionnaires are also given in Tables 1-8 below.

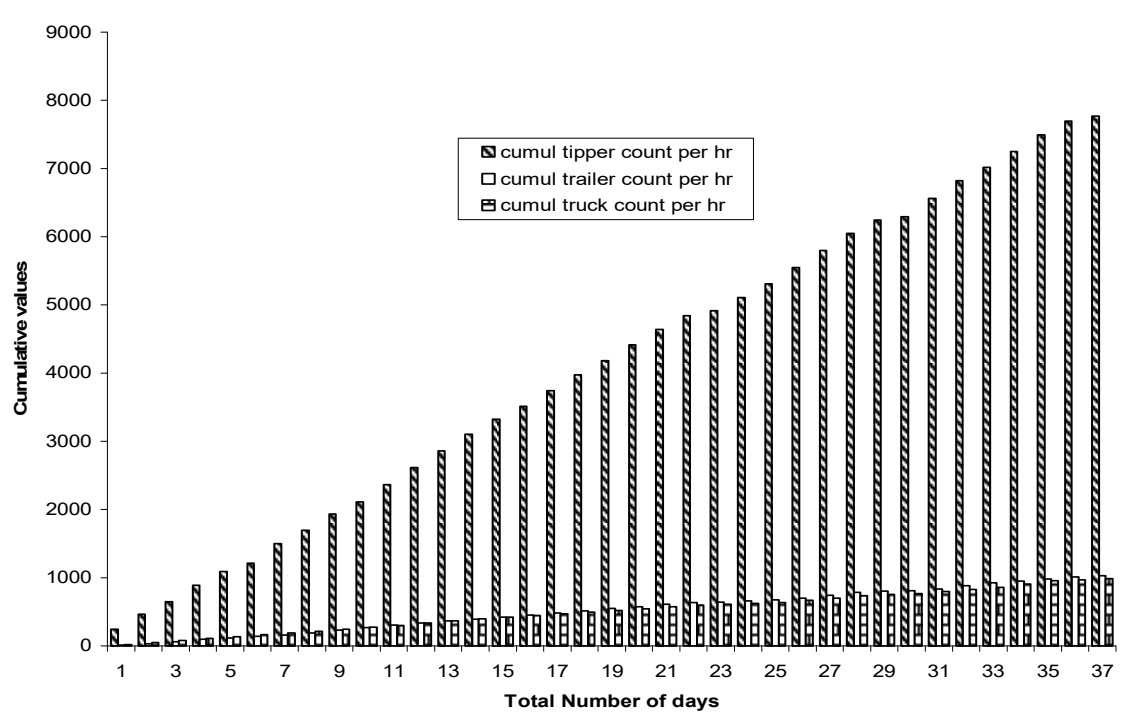

Figure 2: Plot of total vehicle distribution per hour for the whole sampling period.

Table 1: Response of contributors from site 1 on the effects of traffic.

\begin{tabular}{|c|c|c|c|c|c|}
\hline Effect & $\begin{array}{c}\text { Below 20yrs } \\
(25)\end{array}$ & $\begin{array}{c}\text { Between } \\
20-40 \mathrm{yrs} \\
(59)\end{array}$ & $\begin{array}{c}\text { Between } \\
41-60 \mathrm{yrs} \\
(28)\end{array}$ & $\begin{array}{c}\text { Above } \\
\text { 60yrs (2) }\end{array}$ & Total \\
\hline Noise & $25(100 \%)$ & $59(100 \%)$ & $28(100 \%)$ & $2(100 \%)$ & 114 \\
Vibrations & $25(100 \%)$ & $59(100 \%)$ & $28(100 \%)$ & $2(100 \%)$ & 114 \\
Accidents & $25(100 \%)$ & $59(100 \%)$ & $28(100 \%)$ & $2(100 \%)$ & 114 \\
$\begin{array}{c}\text { Carbon } \\
\text { Monoxide } \\
(\mathrm{CO})\end{array}$ & $25(100 \%)$ & $59(100 \%)$ & $28(100 \%)$ & $2(100 \%)$ & 114 \\
\hline
\end{tabular}


Table 2: Response of contributors from site 1 on perceived effects of building vibrations.

\begin{tabular}{|c|c|c|c|c|c|}
\hline Effect & $\begin{array}{c}\text { Below } \\
\text { 20yrs (25) }\end{array}$ & $\begin{array}{c}\text { Between } \\
20-40 \mathrm{yrs} \\
(59)\end{array}$ & $\begin{array}{c}\text { Between } \\
41-60 \mathrm{yrs} \\
(28)\end{array}$ & $\begin{array}{c}\text { Above } \\
60 \mathrm{yrs}(2)\end{array}$ & Total \\
\hline High & $9(36.0 \%)$ & $26(44.1 \%)$ & $6(21.4 \%)$ & $0(0.0 \%)$ & $\begin{array}{c}41 \\
(36.0 \%) \\
73 \\
(64.0 \%)\end{array}$ \\
\hline Low & $16(64.0 \%)$ & $33(55.9 \%)$ & $22(78.6 \%)$ & $\begin{array}{c}2 \\
(100.0 \%)\end{array}$ & $\begin{array}{c}114 \\
(100.0 \%)\end{array}$ \\
\hline
\end{tabular}

Table 3: Response of contributors from site 1 on the perceived agents of building vibrations.

\begin{tabular}{|c|c|c|c|c|c|}
\hline Agent & $\begin{array}{c}\text { Below } \\
20 \text { yrs }(25)\end{array}$ & $\begin{array}{c}\text { Between } 20- \\
40 y r s(59)\end{array}$ & $\begin{array}{c}\text { Between } \\
41-60 y r s \\
(28)\end{array}$ & $\begin{array}{l}\text { Above } \\
60 \mathrm{yrs}(2)\end{array}$ & Total \\
\hline Cars/buses & $6(24.0 \%)$ & $15(25.4 \%)$ & $8(28.6 \%)$ & $0(0.0 \%)$ & $\begin{array}{c}29 \\
(25.4 \%)\end{array}$ \\
\hline $\begin{array}{c}\text { Heavy } \\
\text { vehicles }\end{array}$ & $19(76.0 \%)$ & $44(74.6 \%)$ & $20(71.4 \%)$ & $\begin{array}{c}2 \\
(100.0 \%)\end{array}$ & $\begin{array}{c}85 \\
(74.6 \%)\end{array}$ \\
\hline & & & & Total & $\begin{array}{c}114 \\
(100.0 \%)\end{array}$ \\
\hline
\end{tabular}

Table 4: Response of contributors from site 1 on suggested reducing/elimination measures.

\begin{tabular}{|c|c|c|c|c|c|}
\hline Measure & $\begin{array}{c}\text { Below } \\
20 y r s(25)\end{array}$ & $\begin{array}{c}\text { Between } \\
20-40 y r s \\
(59)\end{array}$ & $\begin{array}{c}\text { Between } \\
41-60 y r s \\
(28)\end{array}$ & $\begin{array}{c}\text { Above } \\
60 y r s(2)\end{array}$ & Total \\
\hline $\begin{array}{c}\text { Impose } \\
\text { speed limits } \\
\begin{array}{c}\text { Carve new } \\
\text { routes }\end{array}\end{array}$ & $6(24.0 \%)$ & $17(28.8 \%)$ & $4(14.3 \%)$ & $0(0.0 \%)$ & $\begin{array}{c}27 \\
(23.7 \%) \\
87\end{array}$ \\
\hline \multicolumn{1}{|c|}{$19(76.0 \%)$} & $42(71.2 \%)$ & $24(85.7 \%)$ & $2(100.0 \%)$ & $\begin{array}{c}87.3 \%) \\
(42.3 \%\end{array}$ & $\begin{array}{c}114 \\
(100.0 \%)\end{array}$ \\
\hline
\end{tabular}


Table 5: Response of contributors from site 2 on the effects of traffic.

\begin{tabular}{|c|c|c|c|c|c|}
\hline Effect & $\begin{array}{c}\text { Below 20yrs } \\
(41)\end{array}$ & $\begin{array}{c}\text { Between } \\
20-40 \mathrm{yrs} \\
(74)\end{array}$ & $\begin{array}{c}\text { Between } \\
41-60 \mathrm{yrs} \\
(20)\end{array}$ & $\begin{array}{c}\text { Above } \\
60 \mathrm{yrs} \\
(7)\end{array}$ & Total \\
\hline Noise & $41(100 \%)$ & $74(100 \%)$ & $20(100 \%)$ & $7(100 \%)$ & 142 \\
Vibrations & $41(100 \%)$ & $74(100 \%)$ & $20(100 \%)$ & $7(100 \%)$ & 142 \\
Accidents & $41(100 \%)$ & $74(100 \%)$ & $20(100 \%)$ & $7(100 \%)$ & 142 \\
$\begin{array}{c}\text { Carbon } \\
\text { Monoxide } \\
(\mathrm{CO})\end{array}$ & $41(100 \%)$ & $74(100 \%)$ & $20(100 \%)$ & $7(100 \%)$ & 142 \\
\hline
\end{tabular}

Table 6: Response of contributors from site 2 on perceived effects of building vibrations.

\begin{tabular}{|c|c|cc|c|c|}
\hline Measure & $\begin{array}{c}\text { Below 20yrs } \\
(41)\end{array}$ & $\begin{array}{c}\text { Between } \\
20-40 \mathrm{yrs} \\
(74)\end{array}$ & $\begin{array}{c}\text { Between } \\
41-60 \mathrm{yrs} \\
(20)\end{array}$ & $\begin{array}{c}\text { Above } \\
60 \mathrm{yrs}(7)\end{array}$ & Total \\
\hline $\begin{array}{c}\text { Impose speed } \\
\text { limits }\end{array}$ & $27(65.9 \%)$ & $\begin{array}{c}39 \\
(52.7 \%)\end{array}$ & $9(45.0 \%)$ & $\begin{array}{c}7 \\
(100.0 \%)\end{array}$ & $\begin{array}{c}82 \\
(57.7 \%)\end{array}$ \\
$\begin{array}{c}\text { Carve new } \\
\text { routes }\end{array}$ & $14(34.1 \%)$ & $\begin{array}{c}35 \\
(47.3 \%)\end{array}$ & $11(55.0 \%)$ & $0(0.0 \%)$ & $\begin{array}{c}60 \\
(42.3 \%)\end{array}$ \\
& & & \multirow{2}{*}{ Total } & $\begin{array}{c}142 \\
(100.0 \%)\end{array}$ \\
\hline
\end{tabular}

Table 7: Response of contributors from site 2 on the perceived agents of building vibrations.

\begin{tabular}{|c|c|c|c|c|c|}
\hline Effect & $\begin{array}{c}\text { Below } \\
20 y r s \\
(41)\end{array}$ & $\begin{array}{c}\text { Between 20- } \\
\text { 40yrs (74) }\end{array}$ & $\begin{array}{c}\text { Between 41- } \\
60 y r s(20)\end{array}$ & $\begin{array}{c}\text { Above } \\
60 y r s(7)\end{array}$ & Total \\
\hline High & $\begin{array}{c}20 \\
(48.8 \%) \\
21\end{array}$ & $46(46.2 \%)$ & $16(80.0 \%)$ & $5(71.4 \%)$ & $87(61.3 \%)$ \\
Low & $28(37.8 \%)$ & $4(20.0 \%)$ & $2(28.6 \%)$ & $55(38.7 \%)$ \\
\hline
\end{tabular}


Table 8: Response of contributors from site 2 on suggested reducing/elimination measures.

\begin{tabular}{|c|c|c|c|c|c|}
\hline Agent & $\begin{array}{c}\text { Below } \\
\text { 20yrs (41) }\end{array}$ & $\begin{array}{c}\text { Between 20- } \\
\text { 40yrs (74) }\end{array}$ & $\begin{array}{c}\text { Between 41- } \\
\text { 60yrs (20) }\end{array}$ & $\begin{array}{c}\text { Above } \\
60 y r s ~(7)\end{array}$ & Total \\
\hline $\begin{array}{c}\text { Cars/Buses } \\
\text { Heavy } \\
\text { Vehicles }\end{array}$ & $1(2.4 \%)$ & $2(2.7 \%)$ & $2(10.0 \%)$ & $0(0.0 \%)$ & $5(3.5 \%)$ \\
7 & $18(90.0 \%)$ & $\begin{array}{c}137(96.5 \%) \\
(100.0 \%)\end{array}$ & $\begin{array}{c}142 \\
\text { Total }\end{array}$ \\
\cline { 5 - 7 }
\end{tabular}

\section{RESULTS AND DISCUSSION}

Tables 1-8 show that all 256 respondents agree to the stated effects of vehicle transportation. However, on the issue of traffic-induced vibrations, all respondents agreed that the phenomenon is very regular, with daily occurrence, but deferred in their knowledge of the degree of effects. Half of the total respondents agree on both sides that its effects could be high or low. More so, $86.7 \%$ (222) of the total respondents agree that, traffic-induced building vibrations are caused by heavy vehicular movements. On the suggested reduction/elimination measures, the respondents differ in opinion. 46.6\% (109) agree to imposition of speed limits, while $57.4 \%$ agree that the authorities should carve out new routes through isolated areas for heavy vehicle transportation. Relating these suggestions to the sites in other to assess individual responses, and have justification for the outcome, brought about a need for the assessment of the individual site's road. Site 1 has a fairly good but narrow road while site 2 has a median in between paved roads. The distance between the buildings and the roads at the sites were mostly less than acceptable standard $(12-15 \mathrm{~m})$. It was also observed on site two that the speeds of vehicle movements were very high. These therefore, accounted for the number of respondents of site 1 agreeing pertinently to the suggestion that a new route should be carved out for heavy vehicle transportation while many of site 2 agreed to imposing speed limits. The results confirm the fact the phenomenon of traffic-induced vibration is prevalent in the areas and in the nation, despite the lack of attention given to it. Also, the results suggest that heavy vehicle speed control measures and/or traffic management is pertinent around the sites.

\subsection{Model development}

On the extent of traffic-induced vibrations, predicting the rate of induction per hr/day is inevitable to understand the probable cumulative effects and foretelling eventual likely outcome in the face of such phenomenon without recourse to much experimentation. This would mean, having a handy model for predictive purposes. Developing such model involves subjecting data from Fig. 2 to a non-linear regression analysis to determine the relationship between the cumulative vehicle count per hr/day and the number of days (given by eqns (1)(3)), and applying necessary assumption

$$
\begin{aligned}
& T_{C P}=-36.13+226.77 D-0.39 D^{2}\left[R^{2}=99.93 \%\right], \\
& T_{C R}=-29.76+30.43 D-0.05 D^{2}\left[R^{2}=99.81 \%\right],
\end{aligned}
$$




$$
T_{C K}=2.33+27.31 D-0.03 D^{2}\left[R^{2}=99.72 \%\right]
$$

where:

$\mathrm{T}_{\mathrm{CP}}, \mathrm{T}_{\mathrm{CR}}$ and $\mathrm{T}_{\mathrm{CK}}$ represent the values of the cumulative tipper, trailer, and truck counts respectively, $\mathrm{D}$ gives the number of days and $\mathrm{R}^{2}$ is the $\mathrm{R}$-square value of the regression at $95 \%$ confidence level which shows that the values of the number of days in the expressions as they are, explains over $99 \%$ of the observable changes in the cumulative volume of vehicle traffic per her/day.

Differentiating these equations to get the maximum vehicular traffic per hr/day gives:

$$
\begin{gathered}
\frac{d T_{C P}}{d D}=226.77-0.77 D, \\
\frac{\mathrm{dT}_{\mathrm{CR}}}{\mathrm{dD}}=30.43-0.1 \mathrm{D}, \\
\frac{\mathrm{dT}_{\mathrm{CK}}}{\mathrm{dD}}=27.31-0.06 \mathrm{D} .
\end{gathered}
$$

The assumption was based on the fact that out of every $\eta$ vehicles, e causes vibration waves to be sent into the building. Thus the probability $(\mathrm{P})$ of a vehicle inducing building vibrations is given as:

$$
P=\frac{e}{\eta}
$$

The total rate of traffic induced vibrations per hr/day $(\vartheta)$ therefore can be given as:

$$
\vartheta=\frac{d T}{d D} \times P .
$$

Combining eqn (8) with eqns (4)-(6) for each of the vehicle types gives:

(i) tipper:

$$
\vartheta_{1}=\frac{d T_{C P}}{d D} \times P_{C P}=\frac{e_{C P}}{\eta_{C P}}(226.77-0.77 D),
$$

trailer

$$
\vartheta_{2}=\frac{\mathrm{dT}_{\mathrm{CR}}}{\mathrm{dD}} \times P_{C R}=\frac{e_{C R}}{\eta_{C R}}(30.43-0.1 D),
$$

truck

$$
\vartheta_{3}=\frac{\mathrm{dT}_{\mathrm{CK}}}{\mathrm{dD}} \times P_{C K}=\frac{e_{C K}}{\eta_{C K}}(27.31-0.06 D) .
$$

The total extent of (cumulative) induced vibrations can be given as:

$$
\vartheta=\sum_{i=1}^{3} \vartheta_{i}=\vartheta_{1}+\vartheta_{2}+\vartheta_{3}
$$

This is given for the particular case of the three different types of vehicles considered as: 


$$
\vartheta=\frac{e_{C P}}{\eta_{C P}}(226.77-0.77 D)+\frac{e_{C R}}{\eta_{C R}}(30.43-0.1 D)+\frac{e_{C K}}{\eta_{C K}}(27.31-0.06 D) .
$$

Eqn (13) is therefore the total rate (extent) of traffic induced vibration per hour/day for site 1 based on the data analysed.

\subsection{Generalizing the model development}

Let $Y_{K}=\sum_{i=1}^{k} y_{i}$ be the cumulative number of vehicles per hr/ day for certain period of days (k).

Let $D_{K}=\sum_{j=1}^{k} d_{i}$ be the cumulative number of days covered for the period $(\mathrm{k})$.

\subsection{Developing the relationship between the $Y_{k}$ and $D_{k}$}

This entails carrying out a non-linear regression analysis to get:

$\Upsilon=a_{0}+a_{1} D+a_{2} D^{2}+a_{3} D^{3}+\ldots \ldots \ldots . .+a_{i} D^{i}$ (the order of the equation depends on the data)

This can be represented generally as:

$$
\Upsilon=\sum_{i=0}^{k} a_{i} D^{i}
$$

where:

$\Upsilon=$ cumulative number of vehicles per $\mathrm{hr} /$ day,

$\mathrm{D}=$ number of days.

3.4 Deriving the expression for the maximum rate of vehicle traffic per hour/day

Entails differentiating the relationship above as:

$$
\frac{d \Upsilon}{d D}=\frac{d}{d D}\left(\sum_{i=0}^{k} a_{i} D^{i}\right) .
$$

\subsection{Applying the assumption to the expression}

This will give the maximum number of times OR simply put "the rate (extent)" the vehicular traffic will induce building vibrations. It is done by multiplying eqn (7) with eqn (14).

Therefore, the total rate of traffic induced vibrations per hour/day can be given as:

$$
\vartheta=\frac{d \Upsilon}{d D} \times P=\frac{d}{d D}\left(\sum_{i=0}^{k} a_{i} D^{i}\right) \times P
$$

This becomes:

$$
\vartheta=\frac{d \Upsilon}{d D} \times \frac{e}{\eta}=\frac{d}{d D}\left(\sum_{i=0}^{k} a_{i} D^{i}\right) \times \frac{e}{\eta} .
$$


Thus, eqn (*) is the Model which can be used to predict the rate (or extent) of trafficinduced building vibrations in an area. The general representation is eqn $(* *)$

$$
\vartheta=\frac{d \Upsilon}{d D} \times \frac{e}{\eta} .
$$

Summarily,

$$
\vartheta=f(t, Y, e),
$$

where $\vartheta=$ Rate of traffic-induced building vibrations, $\mathrm{t}=$ time, $\mathrm{Y}=$ volume of concerned vehicles (Heavy vehicles), $\mathrm{e}=$ volume of vehicles initiating induced building vibrations. This is a stochastic phenomenon (i.e. time based probabilistic phenomenon).

\section{CONCLUSIONS}

The phenomenon of traffic-induced building vibrations has gained attention around the globe with several study reports showing its occurrence in different places. Despite this widespread attention, Nigeria is yet to focus on the issue. All efforts in the nation have always been tailored towards reduction/elimination of road accidents with little or no interest given to incidents of traffic-induced building vibrations. This study was therefore used to assess the people's perception of the incidents of traffic-induced building vibrations in Nigeria with special focus given to the study areas. Its additional aim was to investigate and develop a model to measure, predictively, the level of occurrence and determine the rate/extent of annoyance per period of analysis. Based on this, the development of a predictive model that can be used to evaluate the rate (extent) of traffic-induced building vibrations in Sango-Ota $\left(6.705^{\circ} \mathrm{N}, 3.239^{\circ} \mathrm{E}\right)$ was carried out. Two sites were chosen for the work and questionnaires administered on the people of the sites to access vital information which pertain to their perception on issues ranging from effects of vehicle transportation, causes of traffic-induced vibrations, to suggested reduction/elimination measures of the induced vibrations. Results show that $100 \%$ of the respondents agree to the stated effects of vehicle transportation, while $86.7 \%$ agree that traffic-induced building vibrations are caused by heavy vehicular movements and the opinion of the people differ on the reduction/elimination measures of imposing speed limit or to carve new route through isolated areas for heavy-vehicle transportation.

However, the model developed has limitations which include: its inability to explain the type of vibrations induced (i.e. whether it is airborne or ground borne). It can only predict the (assumed) maximum number of times a particular vehicle induces building vibrations per $\mathrm{hr} /$ day for certain number of such vehicle movement. To differentiate the type of vibrations will require carrying out a vibration characterization study. It can also not explain the extent of damage or impact of the induced vibrations on the buildings but could be used to predict the extent of damage when the damage parameters resulting from such vibrations are known; Another limitation is the fact that the model cannot explain the impact of the induced vibrations on the people inhabiting the buildings. To do this will require an in-depth study of people's reaction to the phenomenon. Moreover, the study was used to create awareness and also spur future investigation into traffic-induced building vibrations in Nigeria.

\section{ACKNOWLEDGEMENT}

The authors would like to acknowledge the support of Covenant University, Ota, Nigeria. 


\section{REFERENCES}

[1] Banks, J.H., Introduction to Transportation Engineering, 2nd ed., McGraw-Hill: New York.

[2] George, E.O., Natural barriers and economic integration in the West African subregion: The case of transportation. Journal of Transport Studies, 2(1), pp. 4-14, 1998.

[3] Okoko, E.O., The demand for Para-transit transport services in Nigerian Towns: Case of motor cycles transport. Journal of Transport Studies, 2(1), pp. 37-44, 1998.

[4] Odugbemi, O.O. \& Ajiboye, A.O., Transport factor in cash crop production and distribution: The Kolanut example. Journal of Transport Studies, 2(1), pp. 89-106, 1998.

[5] Aderamo, A.J., Planning for urban transportation in Nigeria. Perspectives on Urban Transportation in Nigeria, eds I. Vanduchikolo, A.A. Ogunsanya \& A.G. Sumaila, Nigeria Institute of Transport Technology: Kaduna, pp. 312-331, 2004.

[6] Ogunsanya, A. \& Waziri, A., Empirical case studies of accident and safety control of mass transit agencies in Nigeria. Accident Control and Safety Measures in Mass Transit Operations in Nigeria, eds T. Bolade \& A. Ogunsanya, University Press: Ibadan, pp. 87-115, 1991.

[7] Onakomaiya, S.O., General trend of safety and accident records in Nigerian transport sector. Accident Control and Safety Measures in Mass Transit Operations in Nigeria, eds T. Bolade \& A. Ogunsanya, University Press: Ibadan, p. 11, 1991.

[8] Akpoghomeh, O.S., Temporal variation in road traffic accident parameters in the port harcourt metropolis. Journal of Transport Studies, 2(1), pp. 15-36, 1998.

[9] Hunaidi, O. \& Trembley, M., Traffic-induced building vibrations in Montreal. Canadian Journal of Civil Engineering, 24(5), pp. 736-753, 1997. DOI: 10.1139/cjce24-5-736.

[10] Ajayi, O.O., Modelling and simulation of crack initiation and growth in particulate composite: High alloy steels as case study. M. Eng thesis, University of Nigeria: Nsukka, 2003.

[11] Odukwe, A.O., Ajayi, O.O. \& Oluwadare, G.O., Simulation of crack growth rate in martensitic steels. Journal of Applied Sciences, 7(2), pp. 302-305, 2007.

[12] Ajayi, O.O., Constitutive relationship between crack length, number of cycles and stress amplitudes for martensitic steels. Research Journal of Physics, 1(1), pp. 55-59, 2007 DOI 10.3923/rjp.2007.55.59.

[13] Hill, R.C., Traffic induced vibrations in buildings. Noise and Vibration Control Worldwide, 11(5), pp. 176-180, 1980.

[14] Watts, G.R., Traffic Induced Vibrations in Buildings, Transport and Road Research Laboratory. Research Report 246, Berkshire: Crowthorne, 1990.

[15] Al-Hunaidi, M.O., \& Rainer, J.H., Remedial measures of traffic-induced vibrations at a residential site, Part 1: Field tests. Canadian Acoustics, 19(1), pp. 3-13, 1991. 